\title{
Education is a Mediator of Various Cultures: Multicultural Education towards a Humanist Education
}

\author{
Arief Nuryana ${ }^{1}$, Prahastiwi Utari ${ }^{2}$, Pawito $^{3}$, Sudarmo $^{4}$ \\ Postgradute of Communication Studies, Faculty of Sosial Science and Politcal Science, \\ Sebelas Maret University of Surakarta, 36 A Ir. Sutami Road, Surakarta, Indonesia ${ }^{1,2,3,4}$ \\ \{ariefnuryana@gmail.com ${ }^{1}$, prahastiwi@staff.uns.ac.id ${ }^{2}$, pawito@staff.uns.ac.id ${ }^{3}$, \\ sudarmo@staff.uns.ac.id $\left.{ }^{4}\right\}$
}

\begin{abstract}
Studying abroad is a rapidly growing phenomenon and has become one of the main things in the world's higher education. Classrooms are experiencing rapid growth in cultural and ethnic diversity. Because culture directly affects classroom organization and classroom learning, teachers need to understand, incorporate, and support their students' cultures. The findings suggest that significant racial variations in cultural capital and household educational items are largely a function of disparities in family socioeconomic status. Changes in organizational behavior are done by way of adaptation is to adjust to the environment, language, speech patterns and behavior of other students. Experience the language and culture has a major influence on the students' ability to interact and create a new organizational culture. The social inequality that occurs can be reduced with the use of Indonesian as a daily language. The implication for future International students and university is that knowledge about culture and language is a must be prepared and understood. Students and teachers should pass multicultural education programs first define cultural competency before starting teaching and learning activities.
\end{abstract}

Keywords: Multicultural Education, Language, Cultural Identity, Intercultural Communication, Organization Culture

\section{Introduction}

The root of Deep Pluralism the concept of pluralism has occurred with us from the time of the founding of the State of Indonesia on the basis of the State is the 1945 Constitution and Pancasila stands as the beginning of the support of the plural interests in this republic. We see disagreements arising from different perspectives of interest groups as fundamental to the politics of life in the democracy. Pluralism is not only due to the large number of ethnic groups, but also because it consists of various cultural distinctions attached to each ethnicity, both horizontal and vertical [1]. It is influential in fostering pluralistic principles in the Constitution. The separation of powers in the Constitution envisions every branch of government as a counterweight to others Competing group factions and interest are realistically accepted as expressions of aspiration for power. At the same time, there is a more idealistic view that conflict aims to gain strength will lead to a balanced natural harmony of sharing power in society. This study aims to see that Education as a bridge as well as a 
container that pluralism in a smaller scope. For the class program in the post-graduate program, this is more clearly visible with the class as a form of association or a set consisting of students who come from various ethnic, cultural, racial, religious, several of ages in Indonesia and even students who come from abroad. In a broad sense education is equal to life, in the sense of all situations in life that affect one's growth. Education can also be interpreted as the overall learning experience of every person throughout life. In a broad sense, education is equal to life, in the sense of all situations in life that affect one's growth. Education can also be interpreted as the overall learning experience of every person throughout life.

Education does not last within certain age but throughout human life [2]. Multicultural education is etymologically consisting of two words, namely education and culture. Education is simple and general, meaningful as an attempt to cultivate and develop innate, physical and spiritual potentials, in accordance with the values of society and culture. Multicultural interpreted as the diversity of culture, various, and modesty[3] . Studying abroad is a rapidly growing phenomenon and has become one of the main things in the world's higher education. Most universities in the world provide opportunities for students to participate in the development of education worldwide[4]. This is reinforced by research conducted Byram and Feng and Savicky state that study abroad is a phenomenon that is growing rapidly and has become one of the main things in the higher education world [5]. There are many reasons why students choose to study abroad. Positive stories from other students had a great influence in elections to study abroad [6].

In a review of studies abroad, the underlying general assumption in most studies, namely that learners benefit from study abroad because they have opportunities to understand and apply foreign languages in the context of communication [7]. There are several factors causing intercultural communication to foreign students not running well, namely (1) Due to doubts from foreign students to engage in an interaction caused by the perception of the shortage of foreign students caused by lack of ability Foreign language, lack of knowledge about other cultures, reluctance to be an uncomfortable position and poor communication skills (2) Student host seems too busy and not interested to know them, for example: in class discussions and activities, many international students feel Isolated and ignored by their classmates. Particularly related to work in small groups (3) in intercultural interaction with other international students, there is competition to be the best of foreign students campus (4) Presence of cultural insensitivity of host students to foreign students (5) False to identify group members other cultures because of their physical appearance [8]. This is reinforced by the research conducted by Yue, found that cultural differences, inadequate language competence, intercultural understanding, religion, psychological concerns, and racial discrimination are six prominent barriers that prevent international students from engaging in effective and positive interactions [9]. To nurture and maintain understanding among ourselves, we must let go the stereotypical pleasures of some ethnic groups are more virtuous than others and see otherwise in separate way things people do in various situations [10].

Along with the changing concepts of the role of education, there is, perhaps, more importantly, a revolutionary shift in the concept of knowledge. Consensus theory considers the role of education as a form of cultural transformation and the formation of human capital. At school, this is a stage of assimilation that envisions a mono-cultural society and implies the absence of recognition or acceptance of cultural differences based on an unequal dominant subordinate-group relationship. For teacher education, classroom content and technical aspects of classroom management become the focus. Differences in students (race, ethnicity, gender, social class, various ages) are not considered important. However, it is their sense of community that they share, their conceptual analysis of the problems they face and strategies 
for making changes that present, for all to see, the possibility that the world can make a choice in its way of doing it. To be sure, the existence of such a moral community is by no means a victory battle. People who subscribe to an alternative vision of justice and equality are vulnerable, psychologically, socially and in other ways, to ideal standards of hegemonic order which will always be pursued them presently as perverts. But they are a daily reminder of that world. Alternative communities can exist.

\section{Method}

Focusing on the question of: 1 . How is the process of culture through education? and 2. What is the role of education in the cultural process? I will draw on a full year ethnographic study on Post Graduate Class "Management of Communication Science Class of 2016 Universitas Negeri Sebelas Maret, Surakarta. This study was undertaken between September 2016 and September 2017. Thirty-one peoples participated in the study. They were chosen based on the researcher's perception of their ability to articulate their thoughts and experiences and they are all in one class. The selection was also based on diversities in terms of ages and cultures. The class is offered annually as one of the several options for fulfilling a campuswide diversity requirement. Course units included stereotyping/prejudice, various regions in Indonesia, as well as from a variety of ethnic, religious, and of varied age interracial relationships, and racial identity, among others. There were 24 students in the class: 8 females and 16 males. About Sex and Gender, Culture gives specific, local meanings to language by adding shared connotations and associations to the standard denotation of terms. In this way, culture can be understood as a form of community of practice in which certain meanings are privileged above other possible meanings in ways which are relevant to the purposes and histories of the communities of practice. Indonesian world knowledge is by nature embedded and complex, but its operations can be seen through specific instances of communication in which assumed shared world knowledge is fundamental to the message being communicated [11] [12].

The ethnic according to religion composition was twenty-one Moslems, two Christians, and one Hindu, According to the ethnic place where they are from; one student was from Cambodia one student from Bali, one student from West Java, one student from Medan, one student from Jambi, two students from Bengkulu, five students from East Java, there were twelve students from Central Java. The reason researcher divided groups based on the region of origin is Javanese culture has its own characteristics that are different from other cultures. Typical cultural characteristics the society can be observed in Indonesian society consisting of many ethnic groups. Every tribe has its own territorial and cultural areas-something characteristic [13] All lectures are from Central Java. In all, 7 teachers were interviewed. Generally, the respondent's ages ranged from 22 to 65.14 respondents married and had one or more children of school age. And the other 16 are still single. Data collection was mainly through semi-structured interviews. The interview was generally based on the concepts of multiculturalism and multicultural education as perceived by individuals. One Data Collection In concordance with the approach in this study will be conducted using qualitative, descriptive case studies. A qualitative approach is used when the process of research and understanding is based on a methodology to investigate the phenomenon of social and human problems. In this approach, researchers created a complex picture, studying words, a detailed report of the views of informants, and conducting studies on the natural situation [14]. 


\section{Result and discussion}

The themes drawn from the analysis of the data form a basis for the description of the perceptions of respondents regarding the implications of multicultural education for schools. Fifteen themes emerged in the areas of implications. These included: curriculum reform, overhauling of teacher preparation programs, changes in teachers' prejudicial attitudes, censorship of educational and instructional resources, sensitivity to variations in students' learning styles, developing critical thinking and analytical skills, building self-esteem in students, acquisition of diverse language skills, going beyond "culture on the wheel," language, multilingualism, adoption of effective leadership and management practices, and implications for further research.

It is another implication of multicultural education to which more attention should be given. Sensitivity to variations in students' learning styles begins with sensitivity to students' cultural backgrounds. This includes both verbal and nonverbal cues. Studies on culture indicate wide differences in cultural values. "Being quiet in classroom settings should not be mistaken for being a 'dummy' or not being smart. Although it is natural for some people, it is a way of life for others," expressed yet another. Just as an empty barrel makes the loudest noise, the belief is that smart people do not ask questions. It is those who do not understand what has been said or taught that need to ask questions for clarification purposes. A student's avoidance of looking straight into the eyes of the teacher or the elderly in some cultures should not be misconstrued for a sign of guilt, insecurity, non-attention, or uncertainty of answers to questions. Despite the learning of English as a second language, except where such a student happens to be in classes where the teacher is proficient in English and Mandarin, learning may not be effective. This seems to be a common phenomenon in all cultures. Because language is manifested verbally and nonverbally, proficiency in more than one language has the potential of helping a teacher to understand even a garbled expression or decode some culturally related nonverbal cues. There is no doubt that minority students' educational performance has long being constrained by teachers' lack of understanding of the cultures of minority students.

Although most teachers today are competent in their subject areas, they tend to lack adequate knowledge, skills, and attitudes in teaching and managing a diverse student population. If the intent of multicultural education is to put in place a process whereby all students receive equal education, then the evidence to date suggests that traditional approaches to teacher preparation are unlikely to contribute to this goal. Given today's changing demographic composition of students vis-à-vis their diverging needs, greater attention to the professional preparation of teachers becomes imperative. Evidence abounds that teachers of the future will need to be even more skilled than they are today. They will be required to provide adequate professional services to integrate students from various cultures into their classroom. They will also have to learn how to manage a demographically diffused classroom setting. Effective intercultural organizations theory is another variation of the input process analysis model in this research. It focuses on group culture and one's diversity.

The most important cultural difference found in this organization is individualism, collectivism, and self-construal and face concerns. Individualist group members think of themselves as independent. Collectivist tends to focus on organization goals and not on individual goals. This is important in organization communication because the task to be focused on the organization and not in individual goals. The conflict could occur when personal goals interfere. Conflict is a common problem and difficult circumvented in an organization, where between individuals and groups and among groups. After all kind of 
conflicts, both of which interfere or dysfunctional should be eliminated, because in the end would bring chaos and hindering the attainment of organizational goals. The question now is not on the conflict itself, but the way to understand conflicts, avoiding sources of conflicts; detect conflicts and resolving conflicts that arise as early as possible in the very best way. Education is a process of civilizing people so that education is very important for the transfer of culture. Education aims to build the totality of human capabilities, both as individuals and members of society. As a vital element in civilized human life, culture takes its constituent elements from all knowledge which is considered vital and indispensable in interpreting all that exists in its life. Therefore we must preserve and preserve the culture by way of in the process of education in entering the elements of culture.

One of the weaknesses of research on the development of the Multi-cultural Civic model is the amount of students. This makes the researcher must work hard to formulate and classify all aspirations, their basic perceptions and concepts towards Civic learning model corresponding to their desires and the spirit of democratization learning that respects individual and potential their diverse multiculturalism. To obtain maximum results from findings of this research in the conduct innovation and agility development competence of multicultural students through the multicultural based learning model local wisdom in the college environment recommended so conducted research on the more scope broad and involving academic community (lecturers, students and heads of study program) and strengthened by education and learning experts. The researcher's suggestion is a curriculum that includes cultures from different regions of the world by not only theoretically, but also with practices or visualizations such as wearing customary clothing on a particular day, introducing cultures through viewing movies, to bringing people from certain cultures in the classroom.

\subsection{Class New Cultural Form}

The strategy of using a single agreed language is one way to resolve the conflict within the organization. Changes in behavior or habits in the interaction among the members of an organization will create a good culture organization. It is because of an inability to express what role in the members mind because of a limited vocabulary. Consequently, the problem of change is a dimension of content, but also, another dimension, the process one. Therefore, it is creating; at least, three theoretical and methodological approaches to change management, such as its management in a reactive or proactive way, the existence of areas of expertise and professionalism in a non-formal organization such as Classroom. As a reflection on ending exposure to the above, then grasp the concept of organizational change, both business and the public, is very important in maintaining the balance and resilience of the organization to face the challenges of the changing environment, both micro and macro levels, internally and externally, in a controlled manner. Thus these changes can be used as an opportunity and an opportunity, and not a threat that will disrupt the continuity of our organization.

Findings showed speaking from experience when engaged in conversation between students in the class; some students find it difficult to communicate with other students, because of the limited ability of the majority of the students when they communicate daily using the native Javanese language. Focus on the match and mismatch of pedagogical expectations has the merit of leading not only to interesting research possibilities but also to implications for both lectures and students that may lead to more fruitful adaptations by each. The many variables identified suggest pathways for helping students and lectures to enhance the equality in quality of their overall experience. Intercultural communication in this organization is an effective way that play role to cope with culture shock for all the students 
from all regions in Indonesia up to the at this stage of adjustment to the new environments and culture through face to face communication and use of technologies, especially in addressing language problems, to create a new culture.

Obstacles encountered in the process of adaptation and adjustment with a new culture in class is language. If it has been students able to speak Indonesian well and correctly it would be a lot of easier for foreign students, and for the other students that are from various regions in Indonesia, if "Bahasa Indonesia" used as daily basis conversation and not native Javanese instead, it would make a good atmosphere for learning activities in this class. Language is one attribute that sets humans apart from all other creature and binds humans together across all geographic barriers. Each student learns the unique portion of the assignment and shares the information with other students in the group. The method emphasizes open communication, good interpersonal relations, and independent grading to determine what each student has learned from the experience. As teachers, they must see that all students are rewarded for their abilities regardless of social factors such as class, race, and ethnicity, given the adoption of a multicultural curriculum; it is believed that if both teachers and students do not eschew their ethnocentric and prejudicial attitudes, the accomplishment of the goals of multicultural education is doubtful. Unless we renounce our prejudicial attitudes, multicultural education will not work. Because prejudice is a learned behavior, it can be unlearned.

\section{Conclusion}

Teachers must be able to recognize and overcome their prejudices and adopt a more profane way of treating students equally with dignity and respect. Also, teachers should model new and better ways of interacting with people of diverse characteristics, including their students, parents, and professional colleagues. Above all, teachers must desist from judging students' abilities based on perceptions. Communication is established with both fellow students would induce a feeling of calm and homey that helps accelerate the process of adjustment to the environment. This also applies to the administration process so that help accelerates the process so that no misunderstandings or delay of information. A feeling of humility and needs should be developed because it would push for a meeting that ends up creating a good situation in the class. Changing in cultural identity is formed of the class. Changing in cultural identity is formed by an agreement the use of the Indonesian language as the everyday daily language in the classroom form a new culture.

\subsection{Implication}

The foregoing discussion portrays multicultural education as a perfectly awesome approach in its intent and objectives. Given that public schools in the 21 st century will be comprised of a very diverse student population, the implications of the findings of this study, therefore, are for schools to be prepared for a school setting that will be much different than today. That is, tomorrow's schools will be more culturally, racially, and linguistically diverse. Schools should anticipate this movement and incorporate features that address it. Although no single model exists for the teaching of multicultural education in schools, a central implication, however, is that schools should develop strategies that will better serve all students. Schools must recognize their responsibilities to help all children, irrespective of race, culture, color, or place of origin, to develop their unique potentialities to learn. Schools must be committed to 
implementing multiracial and multicultural educational policies that are diverse. They should be open enough to accommodate the changes in the cultural diversities of our society.

The values of Multicultural Education are often contained in every educational activity, the role of the values of multicultural education in the world of education also makes the educators conclude that indeed the object of education that learners have different characteristics that are different about the values of multicultural education. Understanding of what is the value of multicultural education that exists, then it should be attitudes and actions undertaken by educators or teachers does not distinguish what is the difference in all aspects of the object of education ie learners. Educators or teachers are naturally giving love, rights, and justice to all the objects of education or learners in finding differences in them. The values of multicultural education in various educational activities are also considered important to underlie education itself. Multicultural education plays an important role in the world of education because multicultural education here stands as a reference or basis in the ongoing process of education. The basis is due to the existence of multicultural education, the education in Indonesia that there are various tribes, languages, religions, customs, culture, and gender in it is not impossible if there will be a conflict in it caused by the difference, lack of tolerance or absence respect for human rights. So here multicultural education can be an alternative means to solve any conflicts in education related to the differences therein.

By upholding Bhineka Tunggal Ika, the world of education is as good as appreciating the diversity and diversity that will lead to the unity of Indonesia. The role of multicultural education as a foundation in education is also evident as the prevailing media to keep learners from being rooted in cultural roots. Education in this era of globalization is very much incoming foreign education to Indonesia, without reducing the value and existence of that education, so as educators should be able to provide a reference or instill education and culture to learners, so that learners can understand the education and culture of the nation itself before finally getting to know more foreign education. Here multicultural education has a responsibility to prevent the rooting of the cultural roots of Indonesia, of course with all the movements of educators and learners. The language of multiculturalism, Allegations of the supremacy of local citizens and determination to reveal the social a relationship that informs how to speak, how to know and how creature.

As we have seen, some obstacles are blocking their path lecture. Along with the changing concepts of the role of education, there is, perhaps, more importantly, a revolutionary shift in the concept of knowledge, considers the role of education as a form of cultural transformation and the formation of human capital. Multicultural education is not a form of monoculture education, but an educational model that runs on a diversity rail. Therefore, a local identity or a diversified local culture is a content that must exist in the curriculum of multicultural education. Curriculum model that can be used in multicultural education learning is using thematic models. By using thematic models, learners can choose which themes can be developed in accordance with the multicultural conditions that exist in Indonesia. At school, this is a phase of assimilation that envisions a mono-cultural society and implies the absence of recognition or acceptance of cultural differences based on an unequal dominant subordinate-group relationship. Curriculum reform is possibly the most critical factor determining the success of efforts to implement multicultural education. The clamor for a multicultural curriculum, as inferred from this study, is based on the premise that cultural background affects how a child learns and performs academically. Culture embodies the philosophical or worldviews of a people; it is basic to curriculum development. Administrators and teachers in this study expressed a need to know much more about the process of curriculum development and instructional delivery that would address the diverse needs of 
students from all cultures. The curriculum evaluation should include three things, namely product, effect, and impact. Product form student achievement achieved. The effect is a change of behavior at that level higher. The impact is the influence of curriculum on the development of educational institutions and society.

\section{References}

[1] S. A. H. Al Munawar, Fiqih Kehidupan antar Agama Menata Masyarakat Berbasis Multikultural, dalam Masa Depan Bangsa dan Radikalisme Agama. Bandung: Gunung Djati Press, 2006.

[2] R. Mudyaharjo, Pengantar Pendidikan. Jakarta: Rajawali Pers, 2001.

[3] C. Mahfud, Pendidikan Multikultural. Yogyakarta: Pustaka Belajar, 2011.

[4] R. Belyavina, J. Li, and R. Bhandari, New Frontiers: U.S. Students Pursuing Degrees Abroad. New York: Institute of International Education (IIE), 2013.

[5] W. Lihong, Chinese Postgraduate Student in a British University: Their learning Experience and Learning Beliefs. Durham: University, 2010.

[6] C. S. Langley and J. R. Breese, "Interacting sojourners: A study of students studying abroad," Soc. Sci. J., vol. 42, pp. 313-321, 2005.

[7] J. Collentine, The Handbook of Language Teaching. Oxford: Willew-Blackwell, 2009.

[8] H. P. Mary and Greer Norman S, "The Importance of Intercultural Communication in International Education,” Int. Sch. J., vol. XXXII, 2012.

[9] Y. Yun and Le Quynh, "International Students' Social Engagement and Social Wellbeing in an Autralian Regional Area," Int. J. Heal. Wellness Soc., vol. 2, pp. 120 130, 2013.

[10] G. Burnett, "The Scattered members of an Invisible Republic: Virtual Communities and Paul Ricouer's Hermeneutics," Libr. Q., vol. 72, no. 2, pp. 155-24, 2002.

[11] P. Eckert and M. -Ginet Sally, Language and Gender. UK: Cambrige University Press, 2003.

[12] Holmes J and M Meyerhoff, "The community of practice: theories and methodologies in language and gender research." Language in Society, 1999.

[13] Z. Baidhawy, Pendidikan Agama Berwawasan Multikultural. Jakarta: Erlangga, 2005.

[14] Ardial, Paradigma dan Model Penelitian Komunikasi. Jakarta: Bumi Aksara, 2014. 